\title{
Stéphane Lojkine, Image et subversion
}

\section{Gabriella Bosco}

\section{OpenEdition}

\section{Journals}

\section{Edizione digitale}

URL: http://journals.openedition.org/studifrancesi/31028

DOI: 10.4000/studifrancesi.31028

ISSN: 2421-5856

\section{Editore}

Rosenberg \& Sellier

\section{Edizione cartacea}

Data di pubblicazione: 1 avril 2006

Paginazione: 216-217

ISSN: 0039-2944

\section{Notizia bibliografica digitale}

Gabriella Bosco, «Stéphane Lojkine, Image et subversion», Studi Francesi [Online], 148 (XLX | I) | 2006,

online dal 30 novembre 2015, consultato il 18 avril 2021. URL: http://journals.openedition.org/ studifrancesi/31028 ; DOI: https://doi.org/10.4000/studifrancesi.31028

\section{Questo documento è stato generato automaticamente il 18 avril 2021.}

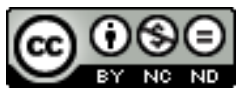

Studi Francesi è distribuita con Licenza Creative Commons Attribuzione - Non commerciale - Non opere derivate 4.0 Internazionale. 


\title{
Stéphane Lojkine, Image et subversion
}

\author{
Gabriella Bosco
}

\section{NOTIZIA}

STÉPHANE LOJKINE, Image et subversion, Paris, Editions Jacqueline Chambon, 2005, pp. 285.

1 Responsabile della banca dati iconografici Utpictura 18 e maître de conférence all'università di Toulouse-le-Mirail, Stéphane LOJKINE dedica un ampio e interessante saggio a un nuovo metodo di analisi dell'immagine, vista non più come supporto di significati prodotti dal linguaggio, ma come produttrice di senso fuori dal linguaggio. L'odierna cultura, basata sull'immagine, rende possibile questo nuovo approccio, sovversivo, che ha il vantaggio di poter essere, senza forzature, retroattivo. Permette cioè di leggere in maniera nuova, alternativa e più efficace, l'iconografia del passato.

Presupposto dell'A. è che esistono svariati sistemi di produzione del senso. Da un sistema all'altro, afferma, non cambiano solo i significanti ma ben più radicalmente cambia la logica semiologica messa in atto. Il discorso è uno dei possibili sistemi semiologici (sistema differenziale fondato sulla successione), le rappresentazioni visive sono un altro e diverso sistema semiologico (sistema sintetico fondato sulla condensazione e lo spostamento). L'opposizione semiologica che interessa LOJKINE non è quella tra due produzioni artistiche diverse, la letteratura e la pittura, ma quella tra due sistemi di produzione di senso al tempo stesso inconciliabili e consustanziali: ordine retorico l'uno, logica dell'immagine l'altro.

Come antidoto all'egemonia della retorica, l'A. propone di non opporre immagini e testi, bensì - all'interno di un medesimo oggetto - la logica retorica alla logica dell'immagine: si vedrà allora come sia ora il reticolato metaforico di un testo a lavorare contro la sua struttura argomentativa, ora il gioco delle forme e dei colori, la disposizione degli oggetti e dei personaggi in una pittura a sovvertire la sua decodificazione allegorica. Non si tratterà più di parlare delle immagini, di isolare qui o là un'immagine, bensì di reperire, analizzare, modellizzare ciò che, a un dato momento, si stacca, si coagula nell'oggetto facendo immagine e, a partire da questo, operando una 
sovversione. L'A. dimostra infatti come la logica semiologica dell'immagine sia necessariamente sovversiva: quando in letteratura, pittura, musica, nell'arte in generale, viene esibita una certa armatura d'ordine retorico, l'ordine dell'immagine comporta sempre un disturbo nella suddetta architettura intima dell'oggetto, perché vi introduce un'altra logica.

4 Al centro del saggio è la nozione di “dispositivo”. A LoJKINE l'immagine interessa per questo fenomeno di disturbo del senso all'interno della rappresentazione che essa opera, per il momento ontologico di denudamento della struttura che essa comporta, e per l'interrogazione etica e la sovversione che essa determina. È sua convinzione che in questi momenti cruciali in cui la struttura si corrompe, in cui l'armatura retorica s'incrina, l'oggetto della rappresentazione invece di dissolversi si riformi nella sua dimensione essenziale che non è quella della struttura ma quella "di ciò in cui la struttura è presa", in altre parole del "dispositivo".

5 Ma passare dalla struttura al dispositivo per analizzare l'oggetto della rappresentazione, comporta una vera e propria rivoluzione metodologica della critica letteraria e artistica. La letterarietà di un testo, come il valore artistico di una pittura o di un'opera musicale nascono infatti dall'interferenza di sistemi semiologici diversi operanti su un unico supporto. Questa interferenza oppone il messaggio artistico "ricco" a quello "semplice", quello cioè riducibile alla sua sola struttura retorica. Il linguaggio viene a essere considerato, nell'ambito del dispositivo, come uno spazio protetto da una sceneggiatura, come del testo preso in un'immagine. Il testo può bloccare e formalizzare l'immagine, ma anche in ogni momento essere sopraffatto da essa.

6 Le modalità dell' inserzione, dell'articolazione del testo in rapporto all'immagine nell'ambito di un dispositivo semiologico, non possono peraltro essere definiti se non in un contesto storico e culturale specifico. In questo saggio, l'A. studia dunque le interferenze di immagine e discorso tra Cinque e Settecento, dal Rinascimento ai Lumi.

7 La funzione sovversiva dell'immagine umanistica, ritiene, può essere teorizzata solo oggi, perché solo oggi è stato infranto l'interdetto teologico-retorico ed è finalmente possibile formulare un modello propriamente iconico della rappresentazione. 